\title{
Retraction Note: Impact of land cover change on the water environment of wetland ecosystem
}

\author{
Jingjing $\mathrm{Ni}^{1}$
}

Published online: 25 November 2021

C) Saudi Society for Geosciences 2021

Retraction Note: Arabian Journal of Geosciences (2021) 14: 1165 https://doi.org/10.1007/s12517-021-07447-y

The Editor-in-Chief and the Publisher have retracted this article because the content of this article is nonsensical. The peer review process was not carried out in accordance with the Publisher's peer review policy. The author has not responded to correspondence regarding this retraction.

The original article can be found online at https://doi.org/10.1007/ s12517-021-07447-y.

$\triangle$ Jingjing Ni

nijingjing7809@163.com

1 The School of Culture and Creativity, Anhui Finance \& Trade Vocational College, Hefei 230601, China 